\title{
An Anatomical Approach to Determine the Location of the Sinoatrial Node During Catheter Ablation
}

\author{
Keiko Shimamoto $^{1}$, Kennichiro Yamagata ${ }^{1}$, Kenzaburo Nakajima $^{1}$, Tsukasa Kamakura ${ }^{1}$, \\ Mitsuru Wada ${ }^{1}$, Yuko Inoue ${ }^{1}$, Koji Miyamoto ${ }^{1}$, Takashi Noda ${ }^{1}$, Satoshi Nagase ${ }^{1}$, and \\ Kengo Kusano ${ }^{1}$ \\ ${ }^{1}$ National Cerebral and Cardiovascular Center
}

November 14, 2020

\begin{abstract}
Introduction: The sinoatrial node (SAN) should be identified before superior vena cava (SVC) isolation to avoid SAN injury. However, its location cannot be identified without restoring sinus rhythm. This study evaluated the usefulness of the anatomically defined SAN by comparing it with the electrically confirmed SAN (e-SAN) and aimed to establish a safe and more efficient anatomical reference for SVC isolation than the previously reported reference of the roof of the right superior pulmonary vein (RSPV roof). Methods and Results: The e-SAN was identified as the earliest activation site in the electro-anatomical map obtained during sinus rhythm. The anatomically defined SAN, the cranial edge of the crista terminalis (CT) visualized with intracardiac echocardiography (CT top), and the RSPV roof were tagged on one map. The distance from the e-SAN to each reference was measured. Among 81 patients, the height of the e-SAN from the CT top was $-3.5 \pm 10.3 \mathrm{~mm}$. The e-SAN existed below $10 \mathrm{~mm}$ above the CT top in 78 (96\%) patients and below the RSPV roof in 77 (95\%) patients. A longer SVC sleeve was measured from $10 \mathrm{~mm}$ above the CT top compared to the RSPV roof $(28.7 \pm 11.2$ vs. $22.5 \pm 11.3 \mathrm{~mm}$, p <0.001). Faster heart rate predicted an e-SAN location higher than the CT top (adjusted OR [95\% CI]; per 10 bpm increase: 1.6 [1.15-2.22], $\mathrm{p}<0.01)$. Conclusion: The CT top is useful in predicting the upper limit of the e-SAN and can provide a useful reference for SVC isolation.
\end{abstract}

\section{Hosted file}

SN__manuscript_JCE.pdf available at https://authorea.com/users/375737/articles/492906-ananatomical-approach-to-determine-the-location-of-the-sinoatrial-node-during-catheterablation 

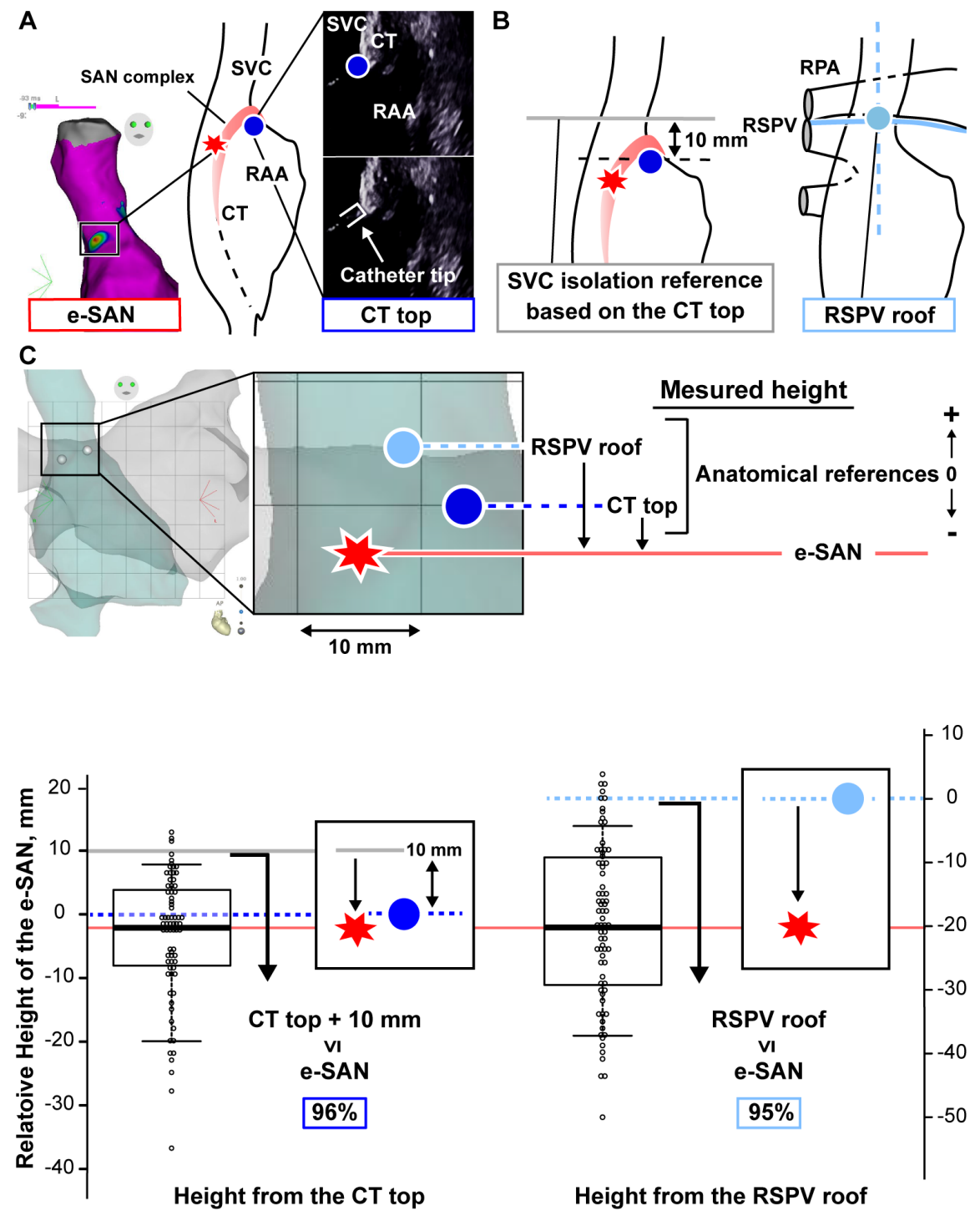

Hosted file

SN_Tables_JCE.pdf available at https://authorea.com/users/375737/articles/492906-ananatomical-approach-to-determine-the-location-of-the-sinoatrial-node-during-catheterablation 